\title{
A Guerra do Contestado na Literatura: as fronteiras entre ficção, história e memória em $O$ Bruxo do Contestado, de Godofredo Oliveira Neto
}

\author{
Sérgio Roberto Massagli \\ Universidade Federal da Fronteira Sul (UFFS), Realeza, Paraná, Brasil \\ sergio.massagli@uffs.edu.br
}

DOI: http://dx.doi.org/10.21165/el.v46i3.1510

\begin{abstract}
Resumo
Em suas célebres teses "Sobre o conceito da História", Walter Benjamin afirma que a história é objeto de uma construção cujo lugar não é o tempo homogêneo e vazio, mas um tempo saturado de "agoras" que fazem explodir o "continuum da história". Assim, podemos dizer que as histórias dos excluídos fazem ecoar na história do Brasil, em explosões sucessivas, gritos marcados pelos mesmos elementos de violência, bravura, desespero, traição e infâmia. Da Balaiada a Canudos, do Cangaço ao Contestado, a história revela as dobras em que esses "agoras" se pregam uns aos outros em um misterioso enredamento. Este artigo se propõe a discutir, ainda que suscintamente, como o romance, enquanto gênero, especialmente o gênero chamado metaficção historiográfica, enfrenta os desafios da narração da memória, individual e coletiva. Para tanto, será analisado, particularmente no plano de sua narração, o romance $O$ bruxo do Contestado, do escritor catarinense Godofredo de Oliveira Neto.
\end{abstract}

Palavras-chave: memória; ficção; história; metaficção historiográfica.

The Contestado War in Literature: the boundaries between fiction, history and memory in $O$ bruxo do Contestado, by Godofredo Oliveira Neto

\begin{abstract}
In his famous thesis "On the Concept of History", Walter Benjamin states that history is the object of a construction whose place is not a homogeneous, empty time, but a time saturated with "nows" that explode the "continuum of history." So, we can say that the histories of excluded people make screams marked by the same elements of violence, bravery, despair, betrayal and infamy echo in Brazil's history, through successive explosions. From Balaiada to Canudos, from Cangaço to Contestado, history reveals the bends in which these "nows" stick together in a mysterious entanglement. This article aims to discuss, albeit succinctly, how the novel, as a genre, especially the genre called historiographical metafiction, faces the challenges of narrating memory, both individual and collective. To do so, we will analyze the process of narration in the novel $O$ bruxo do Contestado, by Godofredo de Oliveira Neto, a writer from Santa Catarina.
\end{abstract}

Keywords: memory; fiction; history; historiographical metafiction.

\section{Narrar: um gesto inelutável e inerente ao ser humano}

Umberto Eco aponta para uma dupla impossibilidade de descrever/narrar o mundo ao dizer que "Não somente é impossível estabelecer um mundo alternativo completo, mas é também impossível descrever o mundo real como completo (ECO apud JOUVE, 2002, p. 61)". Isso significa dizer que assim como um romance (ou qualquer outro gênero) não pode propor um mundo inteiramente diferente do mundo em que vivemos, é igualmente impossível dizer tudo sobre ele. Então por que narrar (ou descrever), se o fracasso é 
inevitável? Já Leyla Perrone-Moisés afirma que "a literatura parte de um real que pretende dizer, falha sempre ao dizê-lo, mas ao falhar diz outra coisa, desvenda um mundo mais real do que aquele que pretendia dizer" (PERRONE-MOISÉS, 1990, p. 102).

Quem se inicia nos estudos literários e nos problemas inerentes à representação do mundo pela linguagem logo se dá conta da impossibilidade de qualquer literatura (incluindo-se aí as chamadas de "não-ficção") ser capaz de reproduzir o real, pois qualquer representação será sempre um recorte e, por conseguinte, qualquer tentativa de apreendê-lo por meio das palavras será sempre, ainda que desvende um mundo "mais real do que aquele que pretendia dizer", incompleta e, portanto, falha.

Independentemente dessa sua incompletude ou falibilidade, a discussão aqui proposta se assenta na universalidade e na inelutabilidade da narrativa e da narração como fatos da cultura humana, o que leva Barthes (1987, p. 103-104) a afirmar:

[...] a narrativa está presente em todos os tempos, em todos os lugares, em todas as sociedades; a narrativa começa com a própria história da humanidade; não há, nunca houve em lugar nenhum povo algum sem narrativa; todas as classes, todos os grupos humanos têm as suas narrativas, muitas vezes essas narrativas são apreciadas em comum por homens de culturas diferentes, até mesmo opostas: a narrativa zomba da boa e da má literatura: internacional, trans-histórica, transcultural, a narrativa está sempre presente, como a vida.

Narrar, portanto, é inerente aos seres humanos. Narramos quase tudo o que vivenciamos, senão para os outros dialogicamente, pelo menos para nós mesmos na forma dos infindáveis monólogos interiores, que constituem a própria matéria do nosso pensamento. O que escapa a esse processo é como se não existisse. Esticando esse argumento ao limite, diríamos que a finalidade última da vida é ser narrada ou então jazer nas sombras do esquecimento. Narrar, portanto, dessa perspectiva exacerbada, é uma questão de vida e morte ou, em outras palavras, menos dramáticas, uma questão de reter e transmitir os acontecimentos vividos ou relegá-los ao olvidamento.

Em seu célebre artigo "O narrador", Walter Benjamin aponta para essa necessidade de narrar como um impulso vital, que remonta às sociedades pré-letradas. Porém, Benjamin não se limita a buscar em sua discussão sobre o ato de narrar os rastros de uma oralidade primeva. Como bem assinala Jeanne Marie Gagnebin, nesse artigo Benjamin não trata necessariamente das técnicas literárias de reprodução da oralidade, mas de "algo anterior à literatura, cronológica e ontologicamente, uma espécie de pulsão - ouso empregar a palavra freudiana Trieb - da narração, cujas formas históricas são certamente mutáveis, mas que persiste mesmo quando sua fonte parece secar, como na contemporaneidade, tão pobre em verdadeiras histórias" (GAGNEBIN, 2014, p. 222223).

Portanto, quando se trata de estudar as narrativas, há que se levar em conta as dimensões antropológicas dessa necessidade humana de narrar suas experiências que preexiste ao fenômeno literário, seja oral ou escrito, como propõe Gagnebin. Há também que se problematizar sua afirmação de que nossa modernidade seja "tão pobre em verdadeiras histórias". Afinal, poderíamos complicar a questão e deixar uma pergunta, quiçá irrespondível: seríamos nós, contemporâneos, pobres em verdadeiras histórias, ou em histórias verdadeiras? 
As intrincadas relações que se estabelecem entre narrar a história e escrever a ficção já foram muito debatidas. Logo no início da década de 1980, Linda Hutcheon (1991) cunhou o termo metaficção historiográfica para designar aqueles romances que problematizam o processo de criação literária e de construção historiográfica, justamente porque colocam em questão aquilo que há de real no texto ficcional e de ficcional nos relatos históricos. A metaficção historiográfica, a partir da desconfiança que alimenta em relação a verdades históricas, suscita a releitura da história a partir de uma perspectiva crítica, que problematize os fatos concebidos como verdadeiros, levando a cabo o questionamento das verdades consideradas históricas e, portanto, inquestionáveis.

Isto posto, este artigo se propõe a discutir, ainda que suscintamente, como o romance, enquanto gênero, especialmente o gênero chamado metaficção historiográfica, enfrenta os desafios da narração da memória, individual e coletiva. Para tanto, será analisado, particularmente no plano de sua narração, o romance $O$ bruxo do Contestado, do escritor catarinense Godofredo de Oliveira Neto.

\section{Nos interstícios da memória, a leitura da história a contrapelo}

Já na década de 1930, Walter Benjamin afirmava, em suas teses "Sobre o conceito da História": "A história é objeto de uma construção cujo lugar não é o tempo homogêneo e vazio, mas um tempo saturado de 'agoras'. Assim, a Roma antiga seria para Robespierre um passado carregado de 'agoras', que ele fez explodir do continuum da história" (BENJAMIN, 2010, p. 229-230). Para dar conta da reconstituição desses "agoras", o cronista deve, segundo Benjamin, considerar que "Nada do que um dia aconteceu pode ser considerado perdido" (BENJAMIN, 2010, p. 223).

Em suas famosas teses, ele afirma que articular esses diferentes "agoras" não significa conhecer o passado "como ele de fato foi", porém "apropriar-se de uma reminiscência, tal como ela relampeja no momento de um perigo" (BENJAMIN, 2010, p. 224), sendo o perigo entendido como o ato de render-se às classes dominantes. Por muito tempo, o historicismo deixou-se dominar pela empatia com os vencedores e é preciso que o cronista que se debruça sobre o passado se esforce para despertar "as centelhas da esperança", consciente de que "os mortos não estarão em paz se o inimigo vencer. E esse inimigo não tem cessado de vencer" (BENJAMIN, 2010, p. 224-225).

Analogamente podemos dizer que as histórias dos excluídos fazem ecoar na história do Brasil, em explosões sucessivas, gritos marcados pelos mesmos elementos de violência, bravura, desespero, traição e infâmia. Da Balaiada a Canudos, do Cangaço ao Contestado, a história, quando lida a contrapelo, revela as dobras em que esses "agoras" se pregam uns aos outros em um misterioso enredamento.

A leitura a contrapelo é uma estratégia para questionar, em sua composição e linguagem, a confiabilidade cega em um único discurso hegemônico e desconstruir algumas narrativas hegemônicas acerca de fatos históricos que se foram construindo e sendo difundidas por instituições e agentes, de maneira consciente ou pela inércia da força ideológica dominante, através do tempo. Esse trabalho de desconstrução, que é a leitura a contrapelo, permite colocar em evidência os contextos de fatos cruciais, principalmente aqueles traumáticos, sob novas perspectivas. 
O conflito conhecido com a Guerra do Contestado é um desses acontecimentos trágicos da história que até hoje inquieta a memória dos mortos. $\mathrm{O}$ evento ocorreu em uma região localizada próximo às fronteiras atuais dos estados do Paraná e Santa Catarina e foi marcado por episódios violentos devido a sua situação de fronteira, aos movimentos migratórios de colonização e à ausência do poder regulador do Estado. Some-se a isso a influência subterrânea da religiosidade popular que, em face de uma situação de precariedade econômica, social e institucional, contribuiu para dotar o movimento dos insurgentes de um forte sentido messiânico. Em suma, tratou-se de um evento histórico complexo, que envolveu religião, política, exploração econômica e disputas territoriais.

Dois aspectos confluem-se, quando se traça um panorama da região do Contestado: de um lado, grande parte do oeste de Santa Catarina - a região entre o Vale do Itajaí, Planalto Serrano e a fronteira com a Argentina - permaneceu, até a segunda década do século XX, uma terra de ninguém devido à baixa densidade populacional; de outro lado, houve uma indefinição territorial tanto na disputa de fronteiras com a Argentina, quanto no litígio de limites de terras entre os estados de Santa Catarina e Paraná. Os dois estados da federação travaram uma longa batalha jurídica e política pela posse desse território, iniciada no período do Império e prolongada na República até o ano de 1917, quando foi feita a demarcação definitiva da região em litígio. Essa querela jurídica sobre a divisa territorial na região contestada é apontada frequentemente como um dos elementos disparadores do conflito.

Entretanto, estabelecer com precisão as causas de um conflito complexo como foi a Guerra do Contestado não se constitui em tarefa fácil. A maioria dos estudiosos converge para uma quase concordância ao apontar questões sociais e políticas como responsáveis pela deflagração da luta armada. É difícil precisar o número de envolvidos no conflito, mas calcula-se em torno de oito mil participantes o contingente rebelde, e em torno de seis mil soldados as forças militares. O número total de mortos, de ambos os lados, pode ter chegado a três mil pessoas (Cf. CABRAL, 1979; QUEIRÓS, 1966; MONTEIRO, 1974). Encerrada a guerra, vaqueanos (jagunços) a mando dos coronéis locais, promoveram perseguições dos remanescentes, que vagavam famélicos e maltrapilhos em bandos pelo interior. A justiça, em conluio com o coronelato, decidia, sem os devidos trâmites processuais, quem ficaria preso ou solto. Por fim, a expropriação de suas terras e a ocultação de sua memória selaram o processo de inferiorização e marginalização das populações caboclas.

Devido às dimensões trágicas da Guerra do Contestado, espanta o fato de ter sido esquecido. Nas décadas subsequentes aos eventos, pairou um silêncio a respeito. As gerações mais recentes, mesmo aquelas que cresceram e se formaram nas regiões do entorno onde a guerra ocorreu, permaneceram sem receber informações sobre o conflito na educação formal, e, ainda hoje, esse acontecimento histórico continua à margem dos manuais de História do Brasil, não obstante o trabalho de muitos estudiosos em manter a sua memória viva, procedendo a um intenso trabalho de revisão os trabalhos realizados pela historiografia mais tradicional.

\section{A releitura e a reescritura da história como forma de resistir ao esquecimento}

Contra tal esquecimento, viu-se eclodirem, nas últimas décadas, produções de cunho artístico e acadêmico que, paulatinamente, começaram a revisar as versões espetaculares e idealizadas da guerra, principalmente, a versão da historiografia 
tradicional - fonte maior na formação da memória oficial sobre o Contestado. Essa versão considerou a guerra "necessária" e mostrou empatia com os vencedores, tratando suas ações como "verdadeiras" e "justas", ao mesmo tempo em que tratou os sertanejos como rudes, analfabetos e fanáticos.

O interesse pela revisão historiográfica surge no meio acadêmico com os trabalhos de Maria Isaura Pereira de Queiroz (1965), que marca o início da mudança na maneira de abordar a Guerra do Contestado, não mais centrada nas teorias das ciências sociais da segunda metade do século passado - em especial, no determinismo biológico, no racismo e no evolucionismo; de Maurício Vinhas de Queirós (1966), que adota uma linha de abordagem ligada à sociologia marxista e aponta como motivo principal do conflito a organização social e econômica da região; de Douglas Teixeira Monteiro (1974) que, ao analisar o conflito, articula o plano social com o simbólico; de Marli Auras (1984) que, a partir do pensamento de Antonio Gramsci, analisa o conflito como uma forma de luta dos caboclos contra a nova ordem capitalista, entre outros.

$\mathrm{Na}$ Literatura, muitos teóricos se esforçaram para compreender as aproximações e os distanciamentos entre a Literatura e a História. O texto História. Ficção. Literatura, de Luiz Costa Lima (2006), por exemplo, traz respostas originais ao desafio teórico de compreender por que a historiografia, devido a sua condição necessariamente discursiva, não pode prescindir da interseção com os domínios da ficção e da literatura. Afinal, assim como a ficção extrapola o domínio da literatura, a história responde a uma necessidade específica do ser humano: conhecer o seu passado. Sem negar que esse conhecimento não se realiza senão num discurso, Costa Lima (2006) ressalta que a história reivindica uma veracidade estranha à ficção. Se o discurso ficcional se caracteriza pela porosidade, o historiográfico trabalha com uma verdade sem poros, numa aporia que ameaça converterse em blindagem contra o autoquestionamento.

Para escapar às armadilhas postas pelo binômio ficção/verdade, William H. Gass, ainda no início dos anos 1970, cunhou o termo metaficção, que veio designar o processo de autorreflexão narrativa (BERNARDO, 2010). O texto metaficcional implica uma fuga à mimese, à representação do real nos moldes da estética romântico-realista, que dominou o romance histórico desde o século dezenove. Desconfia da possibilidade da criação de um retrato exato da realidade, tradução que expressou, no entanto, em determinada época, a concepção burguesa de posse e domínio completo de mecanismos pelos quais o real pudesse ser apropriado e reproduzido.

Em sua obra Poética do Pós-Modernismo: história, poesia, ficção, do início da década de 1980, a canadense Linda Hutcheon (1991) cunhou o termo metaficção historiográfica para designar os romances que se constroem sobre uma dúplice inflexão: de um lado refletem o próprio processo de elaboração artística, daí o caráter metaficcional; de outro, num movimento ambíguo, utilizam a história para, em seguida, contestar a própria veracidade histórica. Trata-se de romances que problematizam o processo de criação literária e de construção historiográfica, ao questionar o que há de verdadeiro no texto ficcional e de ficcional nos relatos históricos.

Para Hutcheon (1991), a separação entre o literário e o histórico é contestada pelas recentes leituras críticas da história e da ficção, concentradas mais naquilo que as duas têm em comum do que em suas diferenças, ou seja, no fato de ambas se manifestarem como discursos sobre o passado, e 
[...] obtêm suas forças a partir da verossimilhança, mais do que a partir de qualquer verdade objetiva; as duas são identificadas como construtos linguísticos, altamente convencionalizadas em suas formas narrativas, e nada transparentes em termos de linguagem ou de estrutura; e parecem ser igualmente intertextuais, desenvolvendo os textos do passado com sua própria textualidade complexa. (HUTCHEON, 1991, p. 141).

Ao conferir primazia à construção linguística da história e deixar em segundo plano o conceito de objetividade histórica, Linda Hutcheon (1991) procura mostrar que só existem verdades no plural, valorizando a narrativa literária como uma das formas de se reconstruir e reler o passado. Diferentemente do que ocorria com o romance histórico tradicional, que se preocupava com conceitos como verdade e falsidade, a metaficção historiográfica problematiza a própria possibilidade de conhecimento histórico, em consonância com práticas historiográficas mais recentes que transformaram por dentro a própria disciplina da História, como a Nova História Cultural e a Micro-história (CHARTIER, 1990; LEVI, 1992; PESAVENTO, 2004; VAINFAS, 2002). Tais práticas propuseram algumas críticas como: a política pensada além das instituições e a história pensada além da política; uma preocupação maior com as estruturas do que com a narrativa dos acontecimentos; deslocamento do interesse pela vida e obra dos grandes homens e grandes datas para as pessoas e acontecimentos comuns; a necessidade de se ir além dos documentos escritos e registros oficiais; a história não seria objetiva, mas sujeita a referenciais sociais e culturais de um período (BURKE, 1992).

\section{Narrando a história pela perspectiva da literatura}

Em seu ensaio "O narrador", Walter Benjamin faz um diagnóstico do ato de narrar na modernidade. Diz ele que nessa época (na modernidade) o narrador autêntico não apenas desapareceu, mas não tem condições de existir porque narrar experiências tornouse impossível. Quanto a esse desaparecimento do narrador, Jeanne Marie Gagnebin observa que Benjamin aponta para o fim do narrador épico, enraizado em sua comunidade, com a qual compartilhava um epos na forma de um relato, oral ou escrito, de feitos e acontecimentos perfeitamente comunicáveis, uma vez que o terreno comum dos valores socialmente aceitos o permitiam.

Na modernidade, quando o "lembrar infinito e coletivo do tempo pré-capitalista cede lugar à narrativa da vida de um indivíduo isolado, que luta pela sobrevivência e pelo sucesso numa sociedade marcada pela concorrência" (GAGNEBIN, 2014, p. 221), o romance é o gênero que ocupará o lugar da narração épica. Assim, como ficou dito logo acima, pode-se dizer que, se o narrador épico desapareceu, algo anterior à literatura, cronológica e ontologicamente, sobreviveu: aquela espécie de pulsão da narração.

Daí que, se em "O narrador", Benjamin lamenta o fim da narração e da memória tradicionais, em outro texto da mesma época, "Experiência e Pobreza", refere-se às experiências da vanguarda e reclama por novas formas de narrar a partir da falência das narrativas tradicionais: "Que moribundos dizem hoje palavras tão duráveis que possam ser transmitidas como um anel, de geração em geração?” (BENJAMIN, 2010, p. 114).

São bem conhecidas as transformações por que passou o romance na segunda metade do século XX, sobretudo na medida em que recuperou a história, que durante a vigência do modernismo tinha sido relegada a uma zona para-literária durante boa parte da primeira metade do século passado. Com o movimento pós-moderno, manifesta-se um 
novo interesse pela problemática histórica, que será abordada com uma liberdade nunca vista no campo da ficção. Essa renovação possibilitará tanto interrogar as versões tradicionais, como preencher as lacunas deixadas pelo discurso histórico oficial.

Deve-se ressaltar que esse novo interesse da literatura pela história coincide, no campo da história, com uma renovação epistemológica do discurso historiográfico que coloca sob suspeita a capacidade da consciência humana de instituir uma história racional, centrada no sujeito; a possibilidade de uma história global como sistema dinâmico, evoluindo organicamente em direção a uma finalidade escatológica; e a própria existência de uma história fora de um discurso efêmero e sempre substituível, porque vítima da própria historicidade.

A partir dessa postura mais autocrítica, a história já não pode ser concebida como discurso do contínuo, do idêntico, mas é o próprio espaço da diferença, em que os objetos (e sujeitos) marginais, antes desconsiderados pela história canônica, ganham visibilidade. Ao mesmo tempo, rompe-se com a ideia de história como resultado de um projeto teleológico desencadeado pelo impulso do progresso. Além disso, reconhece-se que a história confunde-se com o discurso que a toma como objeto e não pode existir fora dele.

\section{O dever de contar as feridas da história que a memória não deixa esquecer}

O romance $O$ bruxo do Contestado, de Godofredo Oliveira Neto, publicado em 1994, faz uma releitura dos fatos históricos da Guerra do Contestado, valendo-se de uma escrita que consciente e sistematicamente chama a atenção para sua condição de artefato, para propor interrogações acerca da relação entre ficção e realidade. Trata-se, portanto, de uma metaficção historiográfica, que, segundo Hutcheon (1991), tem por característica apropriar-se de personagens ou acontecimentos históricos sob a perspectiva da problematização dos fatos concebidos como "verdadeiros". Assim a metaficção historiográfica é caracterizada pela autorreflexão acerca dessas "verdades" e pelo questionamento das verdades históricas. No plano formal, essa forma romanesca é marcada pela adoção de procedimentos e técnicas narrativas, como a descontinuidade, a fragmentação da história e a aproximação entre a alta e a baixa cultura.

Desta maneira, nas fronteiras entre os discursos literário e historiográfico, o romance de Oliveira Neto resgata a história do Contestado deixando-se impregnar pelo imaginário e mostrando que a (re)construção da história não deve ser lugar do idêntico e do contínuo, mas o próprio espaço da diferença e da dispersão identitária, revelando a persistência de relações de poder. Aquilo que a História canônica se esforçou por apagar (os fatos relativos ao conflito do Contestado caíram no mais profundo silêncio por décadas) eclode no livro na forma de uma memória coletiva das múltiplas personagens do romance que rememoram os fatos da Guerra do Contestado. Fato e ficção, realidade e imaginação se interlaçam num complexo polifônico como tentativa de resgatar o passado a partir de diversas perspectivas.

O romance se abre com uma nota anônima, dirigida aos leitores, esclarecendo que essa história havia sido encontrada escrita em um caderno num antigo palacete em demolição na cidade de São Paulo no início dos anos de 1980. O caderno havia sido escrito com caneta-tinteiro azul. Algumas folhas escritas a lápis, em folhas de papel, com o logotipo de um hotel da capital paulista, encontravam-se acrescentadas no corpo do manuscrito. A nota explica que esse ordenamento das páginas avulsas foi rigorosamente 
respeitado na edição do livro, o que resultou na intercalação de duas narrativas, em tempos e espaços diferentes, que se desenrolam paralelamente e são grafadas de maneiras diferentes, a primeira em itálico e a segunda em estilo normal. Essa nota esclarece ainda que a casa pertencia à família Jonhasky, proprietária de uma rede de lojas comerciais, que foram muito ricos e perderam tudo, com o fim da segunda guerra mundial e a deposição de Getúlio Vargas em 1945. Os Jonhasky tiveram dois filhos, Walter Kurt, que foi morar na Alemanha e de quem nunca mais se teve notícia, e Tecla, que residiu vários anos em Nova York, onde morreu de leucemia aos cinquenta e um anos. Tecla é a personagemautora que narra as duas histórias.

Esse recurso narrativo de introduzir o romance com uma nota informando que os manuscritos foram encontrados em algum lugar tem, evidentemente, a função de criar um efeito de realidade e foi muito utilizado no período do Romantismo, tendo sido recuperado mais recentemente pelos pós-modernos.

A primeira narrativa (em itálico) é redigida por Tecla em um hotel em São Paulo no decorrer de 1981. A segunda tem como espaço principal a comunidade de Alto Diamante e os fatos narrados coincidem com o período da Segunda Guerra Mundial, de modo que podemos localizar três tempos históricos, ou temporalidades, distintos que se inter-relacionam no romance: o tempo da narração e da primeira narrativa (1981), o tempo dos eventos narrados e da segunda narrativa (1942-1945) e o tempo da Guerra do Contestado, que atravessa todo o romance (1912-1915). Este último é aquele que proporciona o tema fundante das narrativas posteriores - a Guerra do Contestado, mas não é acessado no romance senão como fatos de memória que são regatados pelas personagens. Nenhuma cena, nenhum fato relativo ao conflito é apresentado senão como memória de terceiros, que não vivenciaram ou presenciaram os acontecimentos.

Ao longo da narrativa principal (ambientada na Era Vargas), percebe-se basicamente três formas de acesso àquela primeira temporalidade do Contestado: uma recalcada, eivada de ressentimento e embebida por um messianismo, que subsiste no personagem Gerd Runnel como fermento para uma nova revolta que possa trazer para a terra o "reino da justiça"; outra, com um viés reacionário, manifestado pela personagem Frau Bertha, que via nos caboclos um foco de sublevação comunista; e uma terceira, mais racional, discutida pelos membros do GDE, uma agremiação de democratas que se reúnem clandestinamente para debater temas relevantes do país.

A forma como essas diferentes temporalidades e as diferentes formas de memórias se engendram no romance é o assunto de Tecla Jonhasky, a "autora-narradora" do manuscrito encontrado. Como sói acontecer em narrativas metaficcionais, essa personagem, que é ao mesmo tempo autora e narradora, joga constantemente com as possibilidades formais e temáticas da obra, demonstrando um alto grau de consciência em relação à produção artística e ao papel a ser desempenhado pelo leitor. Linda Hutcheon (1988, p. 21) afirma que, ao privilegiar a narrativa, a metaficção historiográfica incorpora a ficção, a escrita da história e a teoria literária como elementos sobre os quais a autoconsciência teórica do narrador se constitui.

Em seguida àquela "falsa" nota aos leitores, o romance se abre na forma de um diário, com um cabeçalho: Hotel Levante, São Paulo, 20/01/1981. A narração de Tecla se inicia de maneira dramática: 
Os médicos me deram no máximo seis meses de vida. A doença, no meu caso, não tem cura. Morrerei, pois com cinquenta e um anos. Meus pais também morreram relativamente jovens. Eu tinha que voltar e confiar esta história ao meu país. (OLIVEIRA NETO, 1996, p. 13)

Nota-se aí um tom missionário, exacerbado pela proximidade da morte, que se torna visível pela obrigação auto imposta de regressar e confiar a história que está escrevendo ao seu país. Pode-se falar aqui de um "dever de contar", que se impõe, mais que por um imperativo ético, por uma moral cívica, ou política. Esse dever de contar é a contraparte do dever de lembrar, e ambos estão implícitos no conceito já amplamente conhecido do "dever de memória". Tal conceito surgiu na França logo após a Segunda Guerra Mundial, vinculado a associações de deportados franceses na Segunda Guerra, e que visava honrar a memória de franceses assassinados (LALIEU, 2001, p. 83-94). Posteriormente, esse conceito será reformulado, tendo em vista principalmente a questão do holocausto, e servirá de base para a ação de "outros grupos que buscam afirmar suas memórias no espaço público, memórias que evocam processos de violência ou de discriminação" (HEYMANN, 2007, p. 21).

Para Paul Ricoeur, o dever de memória, assim como outras questões que dizem respeito a uma política da memória, porque lidam com os abusos do esquecimento e à justiça que se deve às vítimas deles, "podem ser colocados sob o título da reapropriação do passado histórico por uma memória instruída pela história, e ferida muitas vezes por ela" (RICOEUR, 2007, p. 01) e "pode ser igualmente expresso como um dever de não esquecer" (RICOEUR, 2007, p. 06). Daí que, como a fábula do anel repassado de geração a geração no leito de morte, contada por Benjamin, Tecla empenhará todo o seu esforço na escrita de suas memórias.

Como se nota pela data do tempo da narração (10/01/1981) e pela insistência em voltar para contar a sua história, o projeto da escrita do livro se insere em um momento especialmente delicado da América Latina em que se trava uma luta entre políticas do lembrar e políticas do esquecer. É o momento de esgotamento das soluções ditatoriais adotadas por vários países (Brasil, Argentina, Uruguai, Chile) e da volta de personagens do cenário político que estavam vivendo no exílio, em que o ato de "lembrar foi uma atividade de restauração dos laços sociais e comunitários perdidos no exílio ou destruídos pela violência de Estado" (SARLO, 2007, p. 45).

Tecla, filha de uma rica família de comerciantes do sul do Brasil, havia se dedicado a atividades subversivas, de resistência à ditadura brasileira, tendo pertencido, no final dos anos sessenta, a uma organização trotskista que atuava em São Paulo e para a qual escrevia panfletos sob o codinome de Bruxo do Flamengo. Esse nome se deveu ao fato de que na sua infância seu pai possuía um "imenso apartamento no bairro do Flamengo, Rio de janeiro, não muito longe do Palácio do Catete", onde recebia membros da Coordenação da Mobilização Econômica, criada por Getúlio Vargas após a declaração de guerra ao Eixo: "Faziam parte dela pessoas conhecidas, como Osvaldo Aranha, Gustavo Capanema, Salgado Filho, Henrique Guilhem, Apolonio Sales, Dutra”. Após um tempo de atividade nessa organização, decide exilar-se. Primeiramente em Estocolmo, onde fica por dois anos, depois em Aarhus, na Dinamarca, onde leciona cultura latinoamericana por mais de dois anos. Em seguida, casa-se com Serge, um judeu marroquino de nacionalidade belga, com quem se muda para Nova Iorque, onde reside até sua volta ao Brasil, já doente. 
Como é característico de narradores de obras metaficcionais, a narradora escritora, Tecla, dedica grande parte de sua narração a citar e dialogar com autores e obras. Assim, aparecem, ao longo da narrativa, um número excessivo de nomes, chegando mesmo a exalar certo pernosticismo. Logo nas páginas introdutórias do romance vai relacionando comentários sobre sua convivência com outros no exílio a referências a autores, obras e personagens da tradição literária. Falando sobre o Harlem: "sempre gostei de andar pelo bairro negro, desafiadora e cúmplice, aliada dos explorados. Sinto até hoje naqueles passeios, Um livro de Guimarães Rosa ou de Jorge Amado (primeira fase!) debaixo do braço, uma ponta de orgulho por ser brasileira". (OLIVEIRA NETO, 1996, p. 16). Com relação ao sentimento de não pertencimento, ela diz: "Mas quer na Dinamarca, quer na Suécia, quer na Dinamarca, eu sempre me senti como Isaías Caminha no Brasil: E tive a sensação de estar em país estrangeiro" (OLIVEIRA NETO, 1996, p. 16). Outros nomes da literatura (e da cultura) vão aparecendo: A montanha mágica, de Thomas Mann; Crime e Castigo, de Dostoievski, Frida Khalo, Diego Rivera, I-Juca Pirama, de Gonçalves Dias, Canto Geral, de Neruda, Maysa, Tchekov (OLIVEIRA NETO, 1996, p. 17).

Além dessas referências literárias, há a referência constante a personagens e fatos históricos: Sousa Dantas, Pinochet, Simon Bolívar, Humboldt, Victor Jara, Canudos, Contestado, República Juliana, que vão se mesclando a referências a personagens fíctícios do próprio romance: os Runnel, Frau Bertha, Elsa, Dieter, Arcângelo.

\section{Considerações finais}

Ao jogar com discursos fronteiriços, como o são o discurso histórico e o literário, o romance $O$ bruxo do Contestado mostra como ambos (e não apenas o literário) deixamse impregnar pelo imaginário e que o discurso histórico, principalmente quando pretende se apresentar como um discurso objetivo e puramente fatual, está a utilizar estratégias de ocultação do seu modo de fabricação e das motivações pulsionais que o engendraram.

Afinal, as fontes sobre as quais ambos se edificam são elas próprias o resultado de um jogo do poder, de ostentação/ocultação, que é preciso despedaçar. O conhecimento histórico é parcial e seletivo e deve ser alargado em direção às zonas que a história oficial se esforçou por apagar. A literatura, especialmente a de caráter metaficcional, pode colaborar nesse trabalho de alargamento ao fazer ficção sobre ficção e, assim, refletir sobre sua própria identidade narrativa e/ou linguística. Mais especificamente, a metaficção historiográfica é capaz de levar essa autorreflexão para a própria história, revelando que há uma linha tênue entre realidade e ficção e que tanto a narrativa histórica como a romanesca são construídas com base em estruturas de verossimilhança, sendo praticamente impossível saber, quando problematizadas, onde começa uma e termina a outra.

Além disso, revela que é ilusório acreditar que possa haver uma identificação possível com as subjetividades do passado, que o fingimento deve ser abandonado a favor de um reconhecimento honesto de que se fala a partir do presente e de que o passado considerado não existe por si próprio, mas é aquele que o presente construiu para o seu próprio uso e em função de desejos e intenções muitas vezes inconfessáveis.

Consequentemente, neste trabalho, foi refutado o método da historiografia tradicional, que se ocupa de um procedimento aditivo e utiliza a massa dos fatos para preencher um tempo homogêneo e vazio. Ao contrário, o que norteou a discussão foi 
explorar os fatos históricos enquanto rememorações enviesadas, marcadas pela experiência individual dos diferentes personagens que, no romance, têm suas experiências marcadas pelos relatos do conflito, já que a narrativa se passa num tempo três décadas posteriores à Guerra do Contestado e nenhum deles a vivenciou diretamente.

Notou-se, portanto, que o projeto do romance não é o de investigar o acontecimento enquanto tal a partir de evidências, indícios, ou quaisquer outros traços físicos referentes ao evento histórico. Trata-se, antes, de acessar as memórias daquele evento como fenômeno de "pós-memória", que Marianne Hirsch (2012) descreve como sendo a relação que uma geração tardia mantém entre o trauma cultural, individual ou coletivo, de uma geração que viveu antes deles e as experiências que estes rememoram somente por meio de histórias, imagens ou comportamentos com os quais conviveram durante a sua vida. No romance, nenhuma cena, nenhum fato relativo ao conflito é apresentado senão como memória de terceiros, que não vivenciaram ou presenciaram os acontecimentos.

Como afirma Pesavento (2004, p. 42), o historiador da cultura "lida com uma temporalidade escoada, com o não-visto, o não-vivido, que só se torna possível acessar através de registros e sinais do passado que chegam até ele". Nesse sentido, em $O$ bruxo do Contestado, o método do romancista não se diferencia daquele do historiador da cultura, o qual assume que o passado só nos chega por meio das representações, sendo possível decodificar a realidade do já vivido por meio delas.

\section{REFERÊNCIAS}

AURAS, M. Guerra do Contestado: a organização da Irmandade Cabocla. Florianópolis: Ed. da UFSC, 1984.

BARTHES, R. A aventura semiológica. BARTHES, R. A aventura semiológica. Tradução de Maria de S. Cruz. Lisboa: Edições 70, 1987. p. 103-104.

BENJAMIN, W. Magia e técnica, arte e política: ensaios sobre literatura e história da cultura. 7. ed. Tradução de Sérgio P. Rouanet. São Paulo: Brasiliense, 2010.

BERNARDO, G. O livro da metaficção. Rio de Janeiro: Tinta Negra Bazar Editorial, 2010.

BURKE, P. Abertura: a nova história, seu passado e seu futuro. In: A escrita da história: novas perspectivas. São Paulo: UNESP, 1992. p. 7-16.

CABRAL, O. R. A campanha do Contestado. Florianópolis: Lunardelli. 1979.

CHARTIER, R. Introdução. In: A história cultural. Lisboa: Difel, 1990.

GAGNEBIN, J.-M. Limiar, aura e rememoração: ensaios sobre Walter Benjamin. São Paulo: Editora 34, 2014.

GINZBURG, C. O queijo e os vermes. São Paulo: Companhia das Letras, 1986.

HEYMANN, L. Q. "O devoir de mémoire na França contemporânea: entre memória, história, legislação e direitos". In: GOMES, A. de C. (Coord.). Direitos e cidadania: memória, política e cultura. Rio de Janeiro: FGV, 2007. p. 15-43. 
HIRSCH, M. The generation of Postmemory, Writing and visual culture after the Holocaust. Columbia University Press, 2012.

HUTCHEON, L. Poética do Pós-Modernismo: história, poesia, ficção. Tradução de Ricardo Cruz. Rio de Janeiro: Imago, 1991.

JOUVE, V. A leitura. São Paulo: Editora UNESP, 2002.

LALIEU, O. "L'invention du “devoir de mémoire". In: Vingtième Siècle. Revue d'histoire, 69, p. 83-94, jan.-mar. 2001.

LEVI, G. Sobre a micro-história. In: BURKE, P. A escrita da história. São Paulo: UNESP, 1992.

LIMA, L. C. História. Ficção. Literatura. São Paulo: Companhia das Letras, 2006.

MONTEIRO, D. T. Os errantes do novo século: um estudo sobre o surto milenarista do Contestado. São Paulo: Duas Cidades, 1974.

OLIVEIRA NETO, G. O Bruxo do Contestado. Rio de Janeiro: Nova Fronteira, 1996.

PESAVENTO, S. J. História e história cultural. Belo Horizonte: Autêntica, 2004.

PERRONE-MOISÉS, Leyla. PERRONE-MOISÉS, L. A criação do texto literário. In: Flores da escrivaninha. São Paulo: Cia. das Letras, 1990.

QUEIROZ, M. I. P. O messianismo no Brasil e no mundo. São Paulo: EDUSP, 1965.

QUEIRÓS, M. V. de. Messianismo e Conflito Social: a Guerra Sertaneja do Contestado. Rio de Janeiro: Civilização Brasileira, 1966.

RICOEUR, P. A memória, a história, o esquecimento. Campinas: Editora da UNICAMP, 2007.

SARLO, B. Tempo passado: cultura da memória e guinada subjetiva. São Paulo: Companhia das Letras, 2007.

VAINFAS, R. Os protagonistas anônimos da história. São Paulo: Campus, 2002.

Recebido em: 13/10/2016

Aprovado em: 29/11/2016 